\title{
Bioresorbable plate fracture after cranioplasty caused by head injury: a pediatric case
}

\author{
Kohei Igarashi ${ }^{1}$, Atsushi Kuge ${ }^{1,2^{*}}$ (D), Hiroshi Homma ${ }^{1}$, Tetsu Yamaki ${ }^{1}$, Rei Kondo ${ }^{1}$, Shinjiro Saito ${ }^{1}$ and
} Yukihiko Sonoda ${ }^{3}$

\begin{abstract}
Background: Recently, bone fixation materials have been developed as surgical materials. Bioabsorbable materials offer several advantages over other materials and are widely used. We report a rare case of the fracture of bioresorbable plates caused by head injury and describe some considerations.

Case description: A 6-year-old boy suffered from consciousness disturbance. He was admitted to our hospital and diagnosed with left frontal subcortical hemorrhage due to ruptured arteriovenous malformation (AVM). He received the surgery of removal of the AVM with decompressive craniectomy. He was discharged without any neurologic deficit and underwent the cranioplasty 4 months after the initial surgery. Two months after the last treatment, he was fallen and hit his left frontal head. The next day, he noticed an abnormal bulge in the injured area. We diagnosed the bulging as cerebrospinal fluid leakage because of the dural tear. The repairment of dural tear was performed. We found that two bioresorbable plates used by cranioplasty were both cracked, and the dura mater beneath them was torn. We repaired the damaged dura with an artificial dura mater. After surgery, cerebrospinal fluid leakage did not occur.

Conclusion: It has been reported that the durability of bioresorbable plates is no less than that of titanium plates. We experienced a relatively rare case in which bioabsorbable plate used for bone fixation was damaged due to head trauma. After craniotomy or cranioplasty using bioresorbable plates, special attention should be paid to head trauma that involves bone flap sinking force and side bending stress.
\end{abstract}

Keywords: Bioresorbable plate, Cranioplasty, Pediatric, Head injury

\section{Introduction}

Various bone fixation materials have been developed [9, 19]. Bioabsorbable plates are slightly less durable than titanium plates but are comparable to titanium plates in osteosynthesis $[1-3,8,13,22]$. Bioresorbable osteofixation materials offer several advantages over titanium

\footnotetext{
* Correspondence: atsukuge@gmail.com

'Department of Neurosurgery, Yamagata City Hospital Saiseikan,

Nanokamachi 1-3-26, Yamagata 990-8533, Japan

${ }^{2}$ Department of Emergency Medicine, Yamagata City Hospital Saiseikan, Nanokamachi 1-3-26, Yamagata 990-8533, Japan

Full list of author information is available at the end of the article
}

fixation, including the absence of the need to remove the implants after osseous healing, radiolucency, and decreased pain. Considering these advantages, the use of bioresorbable plates is increasing, especially in pediatric cases [4]. We report a very rare case of the fracture of bioresorbable plates caused by head injury and describe some considerations.

\section{Case report}

A 5-year and 11-month-old boy presented with left frontal subcortical hematoma due to ruptured AVM

(c) The Author(s). 2021 Open Access This article is licensed under a Creative Commons Attribution 4.0 International License, which permits use, sharing, adaptation, distribution and reproduction in any medium or format, as long as you give appropriate credit to the original author(s) and the source, provide a link to the Creative Commons licence, and indicate if changes were made. The images or other third party material in this article are included in the article's Creative Commons licence, unless indicated otherwise in a credit line to the material. If material is not included in the article's Creative Commons licence and your intended use is not permitted by statutory regulation or exceeds the permitted use, you will need to obtain permission directly from the copyright holder. To view a copy of this licence, visit http://creativecommons.org/licenses/by/4.0/ The Creative Commons Public Domain Dedication waiver (http://creativecommons.org/publicdomain/zero/1.0/) applies to the data made available in this article, unless otherwise stated in a credit line to the data. 


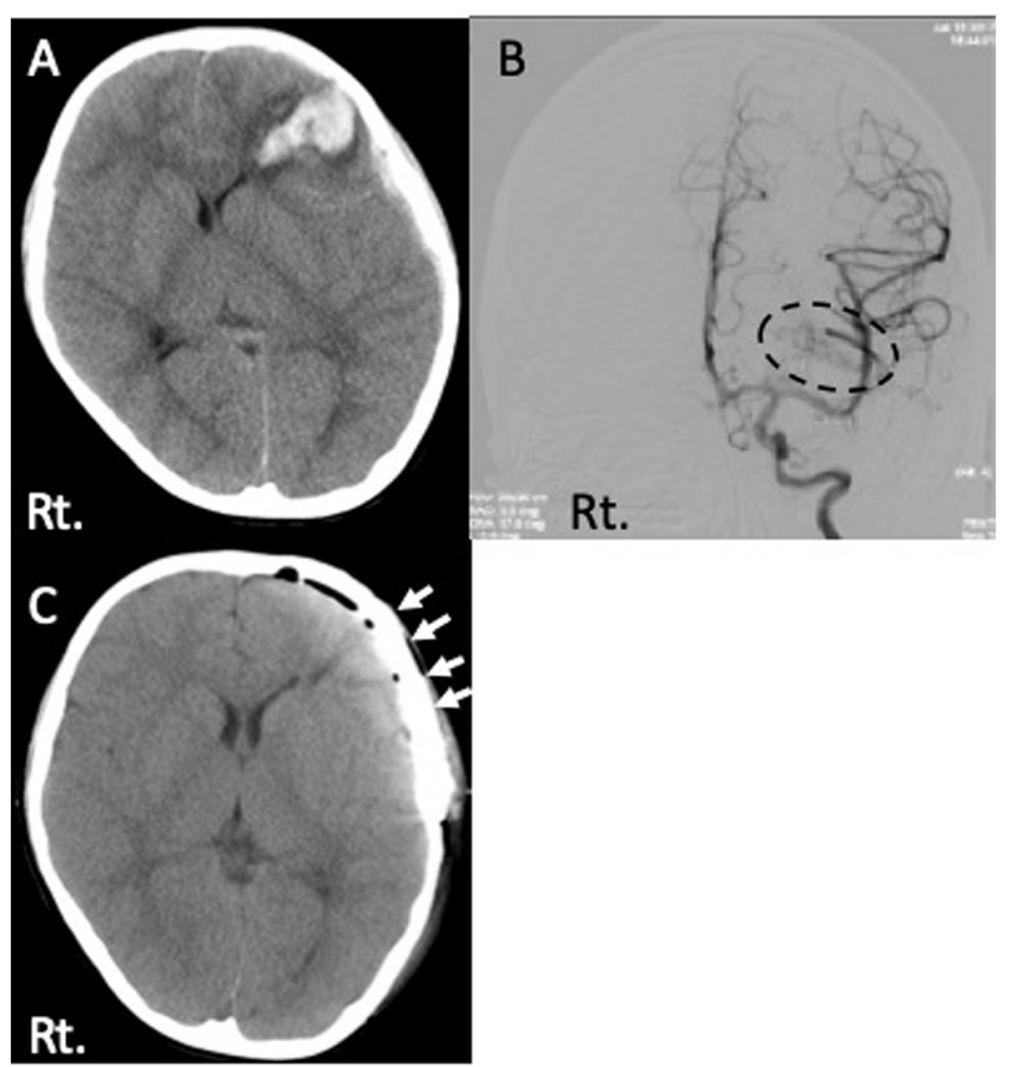

Fig. 1 Radiological examinations at first treatment. a Head CT showed left frontal subcortical hematoma. b Cerebral angiography of the left internal carotid artery showed AVM adjacent to the hematoma (dotted ring). c CT image after cranioplasty

and underwent the removal of AVM with the decompressive craniectomy [Fig. 1a, b]. Four months after the initial surgery, cranioplasty was performed using microporous hydroxyapatite (APACERAM ${ }^{\circ}$ ). We used two bioresorbable plates and eight screws $\left(\right.$ Lactosorb $\left.^{\circ}\right)$ at the frontal region and one titanium plate at the temporal region to fix the artificial bone flap [Fig. 1c]. He was discharged without any neurological deficit after initial treatment.

Nine weeks after the cranioplasty, he hit his left forehead on a refrigerator. The next day, he noticed an abnormal bulge in the injured area. He took a medical check at our department because the bulging area was increased, and there were no signs of recovery. At the time of our check, his consciousness was clear, and he had no other neurologic deficit. The bulging area was located where we performed cranioplasty at the initial treatment. The bulging area was soft, and there were no signs of inflammation.

Head computed tomography (head CT) showed the fluid collection under the scalp and epidural space [Fig. 2]. The CT Hounsfield number of this lesion was low; this finding was suggesting the collection of cerebrospinal fluid rather than that of bleeding. We speculated that the cerebrospinal fluid leakage had occurred due to a dural laceration at the previous surgical site. We decided to surgically repair this lesion based on our speculation.

\section{Operative findings and follow-up}

The previous skin incision was made, and the skin flap was flipped. Though we found no fracture of the artificial bone flap, two bioresorbable plates we used previously were both fractured in the middle [Fig. 3a]. After taking off the bone flap, there was a dural tear at the point of the bone edge, and the cerebrospinal fluid was leaking. [Fig. 3b]. We repaired the injured dura with polyglycolic acid (Dura wave ${ }^{\circ}$ ) with fibrin glue. We fixed the bone flap previously used again by a titanium plate. After the repairment, the bulging area vanished, and he was discharged without any adverse effects. We have followed him for 3 years, no troubles have been seen of his skull. 


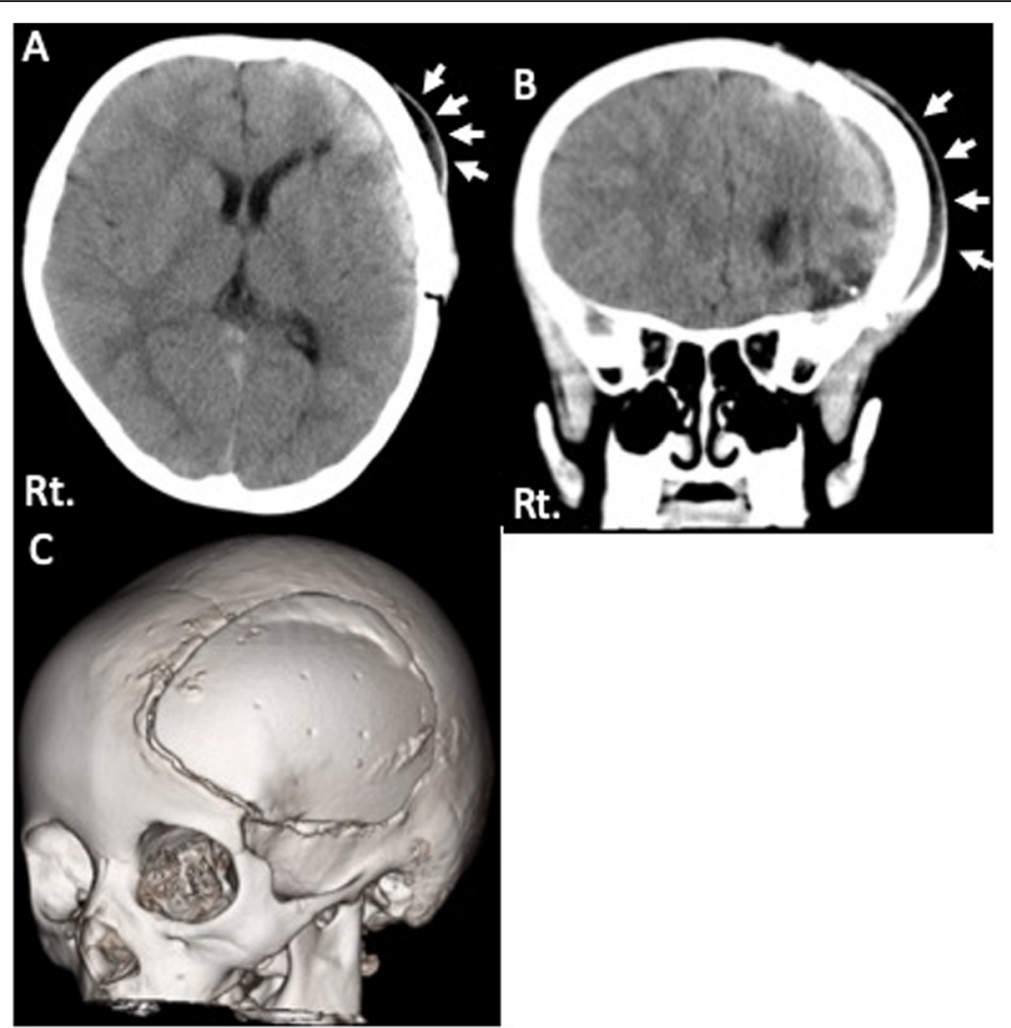

Fig. 2 Radiological examination after head injury. a, b Head CT showed subcutaneous fluid collection (white arrows). c Three-dimensional image showed the relationship between the artificial bone flap and skull. No obvious deviation of the bone flap

\section{Discussion}

When we fixed the bone flap with metal wire or suture thread such as silk or nylon, the fixation was not enough and some problems often happened $[3,9]$. The osteofixation of titanium plates has been developed. Titanium plates are able to fix a bone flap easily but also rigidly. Thus, titanium plates are now widely used at craniotomy. However, adverse events associated with titanium plates are reported especially for pediatric cases implanted for a long period. Especially for periatric patients, these are very important points that adverse outcomes include deviation of the plates, inhibition of cranial bone growth, aberrance into the brain, scalp thinning, and plate exposure $[6,7,9,14,20]$.

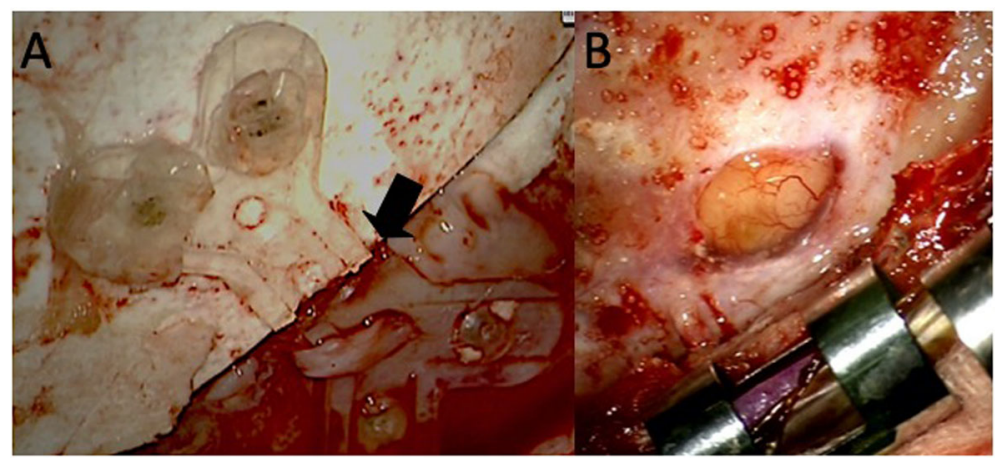

Fig. 3 Intraoperative photos. a Bioresorbable plates were fractured in the middle (black arrow). b The dural tear at the edge of the bone flap and the cerebrospinal fluid was leaking at this point 
Table 1 Comparison of the bioresorbable plate and titanium plate comparison of the bioresorbable plate and titanium plate

Table.1 Comparison of bioresorble plate and titanium plate

Bioresorbable

Fix sterength

Biocompatibility

Radiolucency

Artifact on MRI

Absorption

Technich

Cost rigidly

good

not

much

not

easy

expensive
Titanium

rigidly but inferior

good

have

little

have

complex

very expensive

Recently, various bioresorbable osteofixation implant materials have been developed. It has been reported that polyhydroxyl acids, poly-D-lactic acid, polyglycolic acid, etc. are the materials. The first use of bioresorbable implants to animals was published in 1966 by Kulkarni et al. [11]. Several reports described that adverse effects were not different between bioresorbable and titanium materials, so bioresorbable materials are not inferior to titanium materials $[1-3,8,12,13,22]$. Bioresorbable materials are inferior to titanium in terms of fixing strength, and biocompatibility is not inferior to titanium.

Bioresorbable materials are absorbed in about a year, eliminating the need to remove the implant after osseous healing, and bioabsorbable materials benefit from reduced tactile sensation, pain, and radiolucency. (Table 1) $[4,9,19]$. Because of those advantages described above, the use of them for pediatric cases has been increasing.

Our case showed the fracture of bioresorbable plates after head injury. Lactosorb ${ }^{\circ}$ which we used in this case is made from a copolymer of $82 \%$ poly-L-lactic acid and $18 \%$ polyglycolic acid. In vitro exposure, it is reported that it retains about $70 \%$ of the initial shear strength after 8 weeks. Thus, it is considered that Lactosorb ${ }^{\circ}$ fix strength has retained until natural osseous healing [11, $17,21]$. The time of resorption of the copolymer plate is about a year $[12,14]$. The screws made of the same material have about $80 \%$ of the initial shear strength at 4 weeks and keep the strength after that [18]. It is also reported that bioresorbable plate has similarly bending and tensile stiffness as titanium plate but showed low side bending stiffness of the edges of the bioabsorbable plate [15].

APACERAM $^{\circ}$ which we used as a bone flap at cranioplasty is made from microporous hydroxyapatite. Newly formed bone was detected on the surface of the material and in the macropores near the surface 1 week after transplantation, and it was reported that the compressive strength of $10 \mathrm{MPa}$ is maintained after 5 weeks [21].

This case was injured 8 weeks after the cranioplasty and was thought to have been about $70 \%$ of the initial shear strength of the plate at that time. In this case, it was probable that the bone flap sank due to head injury, and the bioabsorbable plate was subjected to lateral bending stress, resulting in the division at the central part. As a result, the dura mater was injured by the edge of the bone flap and cerebrospinal fluid leakage occurred and made the skin bulge.

By the time the bioabsorbable plate was absorbed, it is thought that bone healing and adhesion to the peripheral bone would progress and shear strength would be maintained $[10,16]$. In this case, the bioabsorbable plate was damaged by a head injury before such a condition occurred. This case indicated that it is necessary to pay much attention to early head injury after cranioplasty with bioresorbable plates. 


\section{Conclusion}

We reported the case of the fracture of bioresorbable plates caused by head injury. After craniotomy or cranioplasty using bioresorbable plates, it is necessary to pay attention to the head injury, especially for bone flap sinking and side bending stress.

\section{Abbreviation \\ AVM: Arteriovenous malformation; CT: Computed tomography}

\section{Authors' contributions}

Kenshi Sano: writing \& editing, Atsushi Kuge: Conceptualization, Writing review \& editing.Rei Kondo: Conceptualization, Supervision. Tetsu Yamaki: Visualization. Hiroshi Homma: Data curation. ShinjiroSaito: Supervision, Writing - review \& editing. Yukihiko Sonoda: Supervision.

\section{Funding}

None.

\section{Declarations}

\section{Ethics approval and consent to participate}

The authors certify that they obtained all appropriate patient and his/her parent's consent forms. The patient and his/her parents understand that their names and initials will not be published, but anonymity cannot be guaranteed.

\section{Competing interests}

The authors declare that they have no competing interests.

\section{Author details}

'Department of Neurosurgery, Yamagata City Hospital Saiseikan, Nanokamachi 1-3-26, Yamagata 990-8533, Japan. ²Department of Emergency Medicine, Yamagata City Hospital Saiseikan, Nanokamachi 1-3-26, Yamagata 990-8533, Japan. ${ }^{3}$ Department of Neurosurgery, Yamagata University, Faculty of Medicine, lidanishi 2-2-2, Yamagata 990-2331, Japan.

Received: 2 April 2021 Accepted: 9 December 2021

Published online: 20 December 2021

\section{References}

1. Aldana PR, Roy S, Postlethwait RA, James HE. Ultrasound-aided fixation of a biodegradable cranial fixation system: uses in pediatric neurosurgery. J Neurosurg Pediatr. 2009;3(5):420-4. https://doi.org/10.3171/2009.2.PEDS0823 0.

2. Ashammakhi N, Renier D, Arnaud E, Marchac D, Ninkovic M, Donaway D, et al. Successful use of biosorb osteofixation devices in 165 cranial and maxillofacial cases: a multicenter report. J Craniofac Surg. 2004;15(4):692701 discussion 702.

3. Dhol WS, Reyneke JP, Tompson B, Sándor GKB. Comparison of titanium and resorbable copolymer fixation after Le Fort I maxillary impaction. Am J Orthod Dentofacial Orthop. 2008;134(1):67-73. https://doi.org/10.1016/j.a jodo.2006.04.049.

4. Eppley BL, Morales L, Wood R, Pensler J, Goldstein J, Havlik RJ, et al. Resorbable PLLA-PGA plate and screw fixation in pediatric craniofacial surgery: clinical experience in 1883 patients. Plast Reconstr Surg. 2003; 114(4):850-6 discussion 857.

5. Eppley BL, Sadove AM. A comparison of resorbable and metallic fixation in healing of calvarial bone grafts. Plast Reconstr Surg. 1995;96(2):316-22. https://doi.org/10.1097/00006534-199508000-00009.

6. Fearon JA, Munro IR, Bruce DA. Observations on the use of rigid fixation for craniofacial deformities in infants and young children. Plast Reconstr Surg. 1995;95(4):634-7 discussion 638.

7. Goldberg DS, Bartlett S, Yu JC, Hunter JV, Whitaker LA. Critical review of microfixation in pediatric craniofacial surgery. J Craniofac Surg. 1995;6(4): 301-7 discussion 308.

8. Habal MB. Absorbable, invisible, and flexible plating system for the craniofacial skeleton. J Craniofac Surg. 1997 Mar;8(2):121-6. https://doi.org/1 0.1097/00001665-199703000-00011.
9. Kanno T, Sukegawa S, Furuki Y, Nariai Y, Sekine J. Overview of innovative advances in bioresorbable plate systems for oral and maxillofacial surgery. Jpn Dent Sci Rev. 2018;54(3):127-38. https://doi.org/10.1016/j.jdsr.2018.03. 003.

10. Ko A, Nerva D, Chang JJJ, Chesnut RM. Traumatic fracture of a polymethyl methacrylate patient-specific cranioplasty implant. World Neurosurg. 2014 82:536.e11-3.

11. Kulkarni RK, Pani KC, Neuman C, Leonard F. Polylactic acid for surgical implants. Arch Surg. 1996;93(5):839-43.

12. Leiggener CS, Curtis R, Müller AA, Pfluger D, Gogolewski S, Rahn BA. Influence of copolymer composition of polylactide implants on cranial bone regeneration. Biomaterials. 2006 Jan;27(2):202-7. https://doi.org/10.1016/j. biomaterials.2005.05.068.

13. Lerch KD. Reliability of cranial flap fixation techniques: comparative experimental evaluation of suturing, titanium miniplates, and a new rivetlike titanium clamp (CranioFix): technical note. Neurosurgery. 1999;44(4): 902-5. https://doi.org/10.1097/00006123-199904000-00137.

14. Marschall MA, Chidyllo SA, Figueroa AA, Cohen M. Long-term effects of rigid fixation on the growing craniomaxillofacial skeleton. J Craniofac Surg. 1991:2(2):63-8 discussion 69-70.

15. Oe M. Comparison of mechanical stiffness of titanium and biodegradable osteofixation systems. J Jpn Soc Plastic Reconstr Surg. 2013;33:219-27.

16. Petridis AK, Barth H, Doukas A, Mehdorn HM. Broken bioceramic used in a computer-assisted reconstruction of the frontal skull bone. J Clin Neurosci. 2009;16(8):1089-90. https://doi.org/10.1016/j.jocn.2008.08.006.

17. Pietrzak WA, Caminear DS, Perns SV. Mechanical characteristics of an absorbable copolymer internal fixation pin. J Foot Ankle Surg. 2002;41(6): 379-88. https://doi.org/10.1016/S1067-2516(02)80084-9.

18. Pietrzak WA, Eppley BL. Stability of craniofacial PLLA/PGA copolymer bioabsorbable screws. J Craniofac Surg. 2006 Mar;17(2):331-6. https://doi. org/10.1097/00001665-200603000-00021.

19. Pina S, Ferreira JMF. Bioresorbable plates and screws for clinical applications: a review. J Healthc Eng. 2012;3:243-60. https://doi.org/10.1260/2040-22 95.3.2.243.

20. Wakui D, Nagashima D, Ueda T, Takada T, Tanaka Y, Hashimoto T. Three cases of scalp rupture and cosmetic deformity caused by a fixation plate after craniotomy. Jpn J Neurosurg. 2012;21(2):138-42. https://doi.org/10. 7887/jcns.21.138.

21. Yamasaki N, Hirao M, Nanno K, Sugiyasu K, Tamai N, Hashimoto N, et al. A comparative assessment of synthetic ceramic bone substitutes with different composition and microstructure in rabbit femoral condyle model. J Biomed Mater Res Part B Appl Biomater. 2009 Nov;91(2):788-98. https://doi. org/10.1002/jbm.b.31457.

22. Yang $L, X u M$, Jin $X, X u J$, Lu J, Zhang $C$, et al. Complications of absorbable fixation in maxillofacial surgery: a meta-analysis. Public Libr Sci ONE. 2013; 8(6):e67449.

\section{Publisher's Note}

Springer Nature remains neutral with regard to jurisdictional claims in published maps and institutional affiliations.

Ready to submit your research? Choose BMC and benefit from:

- fast, convenient online submission

- thorough peer review by experienced researchers in your field

- rapid publication on acceptance

- support for research data, including large and complex data types

- gold Open Access which fosters wider collaboration and increased citations

- maximum visibility for your research: over $100 \mathrm{M}$ website views per year

At BMC, research is always in progress.

Learn more biomedcentral.com/submissions 